arrives when his own judgment is in a certain manner affected by the continual practice which he has to undergo. Heredotus informs us, that among the Egyptians it was customary for medical practitioners to devote themselves exclusively to the treatment of one particular part of the human body and its woes. Is it not probable that, in the course of his experience, the stomach doctor would begin to look upon all men as affected in his chosen region, and the aurist to come to the conclusion that all men were, in one way or the other, partly or 'generally' deaf? In the same way Dr. Winslow is fast arriving at a very literal application of the phrase, ' $A$ mad world, my masters.' Constant ministering to diseased minds appears to be superinducing with him a belief that most minds, if there be but an opportunity of probing them, will turn out unsound. He is by no means the first physician devoted to this branch of medical inquiry in whom a tendency of this nature has manifested itself; but it must be confessed that it has rarely been carried to a greater and more bewildering height.

“The evidence of Drs. Winslow and Gisborne was that on which it was sought to procure Townley's acquittal. The attempt failed; but enough had been said to make the presiding judge doubt whether farther inquiry as to the prisoner's actual state of mind might not be desirable, and to fill the active friends of the prisoner and his able adviser with good hopes, if they set in action the forgotten machinery of a private magisterial and medical inquiry. Thus the murderer's life was saved, at the expense of a public scandal and bitter discontent among large classes of the population. One of the lessons to be learnt from the whole is, the necessity of carefully watching the growth of scientific theories, which apparently rest on no sufficient basis. If Dr. Forbes Winslow's theories are correct, it may be that they should be acted upon in despite of the dangerous consequences which must thence accrue to society at large. If they are unfounded (and few but poor Dr Gisborne have as yet been found to show a determined disposition to 'err with' the 'Plato' of lunacy), it becomes the duty of all who can meet him on even ground and with equal arms, to prove them such to the final satisfaction of the public, and to the unanswerable refutation of the champion of moral monomaniacs."-The Glasgow Medical Journal, April, 1864.

\title{
Homicide in Asylums.
}

Durisg the current quarter two cases have been reported of homicide in asylums. The first case is that of Daniel Hobbs, who, on the 5th of May, killed another patient, John Swinney Phillips at Colney Hatch, by striking him on the head with a piece of gas-pipe which he had pulled down in the water-closet. According to Dr. Sheppard's evidence they were both suffering from the mania of general paralysis. This case was fully investigated before Dr. Lankester and a coroner's jury, and attracted much notice from the press.

The second case occurred at Hanwell, and was brought to trial at the Central Criminal Court on the 8th June. J. P. Knight who had been a patient at Hanwell since the 22nd Oct., and was admitted (according to Dr. Beyley's evidence) in a state of chronic mania with delusions, was indicted for the manslaughter of another lunatic in Hanwell. They slept in a five-bedded dormitory, and in the middle of the night, Knight removed the deceased from one bed to another, and then jumped upon, and suffocated him. The jury immediately returned a verdict that he was in- 
万人

sane, and Mr. Justice Crampton ordered that he be detained in custody during Her Majesty's pleasure. The press gave no attention to this case.

To any one familiar with the details of a large asylum it can only be a cause of mingled wonder and thankfulness that such accidents are not of daily occurrence. With reference to the latter case it is to be observed that the increasing introduction of large dormitories, while conducive to economy alike in construction and management and often valua. ble in the treatment of dirty habits, nevertheless adds materially to the risk of such accidents. One night attendant for 200 patients, which is the average allowance, cannot of course be held responsible for the safety of every patient. Experience, however, teaches us to our comfort that the average of such acts of violence is singularly small. Still, as in the case of suicides they do occur, and no precautions will entirely prevent their recurrence.

\section{Insane Colonies in France.}

"WE have heard much of the advantages and disadvantages of the insane colonies so long established at Gheel; and it seems that the French Government has resolved to introduce the system. The Conncil General of the Rhone has recently, with the approval of the Minister of the Interior, voted the funds necessary for placing out among families one hundred indigent insane persons whose mental condition does not necessitate their sequestration in an asylum. Upon the recommendation of the chief physician, the indigent insane, recognised as incurable and inoffensive, are to be removed from the Antiquaille asylum, at present overcrowded with patients, and placed out. ' Without doubt, ob. serves M. Garnier, in the 'Union Medicale,' 'this example will become promptly contagious; and this will be much to be commended, providing that there be constituted a medical and administrative inspection of these patients as in the case of foundlings. Unable to restore their moral health to these poor creatures, we can at least provide for their physical well-being by this family regimen, life in the open air and varied labours, which are more likely to conduce to it than the residence in an asylum. For the safety of the families concerned and the success of the experiment, care must be taken that the persons selected are both incurable and harmless." "-Medical Times and Garette, May 28.

\section{Proposed Supplementary Asylum in the County of Gloucester.}

“THE Visitors of the Gloucester County Lunatic asylum having taken into consideration the questions submitted to them by the last Court of Quarter Sessions, and having called to their assistance Dr. Williams, the Consulting.Physician and late Superintendent, and Mr. Toller, the Superintendent of the asylum, report-

" That the County asylum is not capable of accommodating more than thirty male patients beyond its present inmates, and that the female side is full ; than no large addition could be made to the present build. ing without entailing great evils and inconveniences not counterbalanced by any adequate economical advantages, since new kitchens, laundry, and other offices would in such case, be required, with the necessity of purchasing many acres of land in a most expensive locality. 